\title{
RANCANG BANGUN SISTEM INFORMASI PENJUALAN PADA PT. DUTA PERFUME BERBASIS WEB MENGGUNAKAN METODE SEKUENSIAL LINIER
}

\section{Design Of Sales Information Systems Web-Based At PT. Duta Perfume Using Linear Sequential Methods}

\author{
Muhammad Fathur Payuda, faturprayuda@trilogi.ac.id ${ }^{1)}$, Egie Hermawan²), \\ Mochammad Aldisetya ${ }^{3)}$, Yaddarabullah, yaddarabullah@trilogi.ac.id ${ }^{4)}$ \\ ${ }^{122) 334)}$ Teknik Informatika, Fakultas Industri Kreatif dan Telematika, Universitas Trilogi
}

\begin{abstract}
Problems that hamper the progress of sales can be overcome because online marketing knows no boundaries, makes it easier to find consumers, promotions, and business transactions to overcome problems in sales of products produced by a company. With online marketing, small entrepreneurs like $U M K M-K$ can raise their names so that they can be better known to people outside their environment. So that sales of goods can increase which can make the MSME-K business become more advanced and can expand its business. As in PT.Duta Perfume Store which is a private company which is engaged in selling perfume or perfume. Therefore PT. Duta Perfume has the problem of how that business can be expanded to get customers both in the place and in other areas to buy the product. To overcome this problem, PT. Duta Perfume wants to create and build an information system that is more precisely engaged in online. This research will build a web-based information system using a linear sequential method, the implementation process is done by using visual studio code as a text editor, using the PHP programming language and organizing RDBMS using MySQL. The testing process uses the black-box testing method. The results of this study can help sales of PT. Duta Perfume in utilizing online marketing using ecommerce technology.
\end{abstract}

Keyword : e-commerce, Information Systems, Perfume, Linear Sequential

\begin{abstract}
ABSTRAK
Permasalahan yang menghambat kemajuan penjualan dapat teratasi karena online marketing tidak mengenal batas wilayah, mempermudah mencari konsumen, promosi, serta transaksi bisnis untuk mengatasi permasalahan dalam penjualan tentang produk-produk yang di hasilkan oleh suatu perusahaan. Dengan adanya online marketing, pengusaha-pengusaha kecil seperti UMKM-K dapat menaikkan nama agar dapat lebih dikenal oleh masyarakat diluar lingkungannya. Sehingga penjualan barang dapat meningkat yang dapat membuaat usaha UMKM-K menjadi lebih maju dan dapat memperluas usahannya. Seperti yang ada pada Toko PT.Duta Perfume yang merupakan perusahaan swasta yang mana bergerak di bidang penjualan perfume atau minyak wangi. Karena itu Toko PT. Duta Perfume memiliki permasalahan bagaimana agar usaha tersebut bisa diperluas dalam mendapatkan customer baik di tempat tersebut maupun di daerah lain untuk membeli produk tersebut. Untuk mengatasi masalah tersebut Toko PT. Duta Perfume ingin membuat serta membangun sebuah sistem informasi yang lebih tepatnya bergerak dibidang online. Pada penelitian ini akan membangun sistem informasi berbasis web menggunkan metode sekuensial linear, proses implementasi dilakukan dengan menggunakkan visual studio code sebagai text editor, menggunakan bahasa program PHP dan pengorganisasian RDBMS menggunakan MySQL. Proses pengujiannya menggunakan metode black-box testing. Hasil dari penelitian ini dapat membantu penjualan PT. Duta Perfume dalam memanfaatkan online marketing (pemasaran online) dengan menggunakan teknologi e-commerce.
\end{abstract}

Kata Kunci: e-commerce, Sistem Informasi, Perfume, Sekuensial Linear 


\section{PENDAHULUAN}

Penggunaan internet sebagai media teknologi informasi dapat membantu penjualan perfume dalam memanfaatkan online marketing (pemasaran online) dengan menggunakan teknologi $e$ commerce Permasalahan yang menghambat kemajuan penjualan dapat teratasi karena online marketing tidak mengenal batas wilayah, mempermudah mencari konsumen, promosi, serta transaksi bisnis untuk mengatasi permasalahan dalam penjualan tentang produk-produk yang di hasilkan oleh suatu perusahaan. Membangun portal e-commerce yang beraktivitas didalam dunia perdagangan yang mengintegrasikan semua jenis informasi. Berdasarkan data Badan Pusat Statistik, perkembangan Unit Usaha Mikro, Krcil, dan Menengah(UMKM) serta Usaha Besar(UB) pada tahun 2016-2017 terdapat 62.928.077 usaha yang ada di Indonesia. Dengan adanya e-commerce, diharapkan UMKM dan UB di Indonesia terus meningkat. Saat ini, pembuatan $e$ commerce berbasis web sudah banyak saat ini. Hal ini dapat dilihat dari publikasi penelitian Rancang Bangun Portal ECommerce Semarang-Handycraft Berorientasi Obyek [1]. Penelitian sebelumnya berfokus pada rancangan pembuatan suatu e-commerce. Pembuatan Sistem Informasi Penjualan Parfum pada PT. Duta Perfume berbasis Web menggunakan metode Squencial Linier yang menggunakan model waterfall untuk pengembangannya. Toko PT.Duta Parfum ini merupakan perusahaan swasta yang bergerak di bidang penjualan perfume atau minyak wangi. Toko tersebut masih memerlukan hal-hal perluasan dalam usaha penjualan produk tersebut. Karena itu Toko PT. Duta Parfum memiliki permasalahan bagaimana agar usaha tersebut bisa diperluas dalam mendapatkan customer baik di tempat tersebut maupun di daerah lain yang datang untuk membeli produk tersebut. Untuk mengatasi masalah tersebut Toko PT.Duta Parfum ingin membuat serta membangun sebuah sistem informasi yang lebih tepatnya bergerak dibidang online pula untuk mempromosikan produk-produk yang ada di toko tersebut. Dengan dirancang dan dibangunnya e-commerce pada toko tersebut dapat dimanfaatkannya sebagai sebuah sarana untuk mempromosikan produk pada toko tersebut agar bisa dikenal luas dan diketahui oleh banyak customer[2].

Berdasarkan pernyatan dari latar belakang tersebut, maka dari itu dapat disusun sebuah rumusan permasalahan yang akan dibahas dalam penelitian ini, diantaranya :

a. Bagaimana merancang dan menerapkan sebuah teknologi sistem informasi berbasis yang menyajikan penawaran produk, harga produk dan transaksi yang dilakukan oleh yang bersangkutan berbasis web e-commerce

b. Bagaimana cara mempermudah pemiliki toko untuk mempromosikan tempat usahanya serta produk-produknya dan juga mempermudah customer untuk melakukan transaksi tanpa harus datang ke tempat tersebut.

Penelitian rancang bangun sistem informasi penjualan parfum pada PT. Duta Parfum ini bertujuan untuk untuk mempermudah si pemiliki toko untuk mempromosikan tempat usahanya serta produk-produknya.

Rancang Bangun dan pembuatan sistem informasi penjualan parfum pada PT. Duta Parfum ini hanya sebatas 2 batasan masalah, diantaranya :

1. Sistem informasi pemasaran yang berwujud kemudahan prasarana bisnis selang PT tersebut terhadap masyarakat.

2. Hasil produksi di propagandakan dan disebarkan luaskan agar customer mengetahui melalui sistem informasi

Tujuan dibuatnya penelitian ini adalah guna membuat sebuah rancang bangun atau rancangan sebuah sistem informasi penjualan / pemasaran e-commerce berbasis website dengan metode waterfall menggunakan PHP dan MySQL pada PT.Duta Parfum tersebut. Perancangan sistem informasi ini bertujuan supaya 
mempermudah pelanggan untuk menemukan dan memperoleh produk yang dibutuhkan dan diinginkan serta pelanggan dapat mengetahui produk apa saja yang diproduksi sehingga tidak perlu untuk datang langsung ke toko[3]. Meringankan serta membantu mempropagandakan area pada PT.Duta Parfum tersebut. Meringankan operasi pembelian dan pemesanan barang oleh para pelanggan sehingga tidak perlu menunggu untuk memesan barang tersebut. Bisa menjadi semacam fasilitas untuk transaksi bisnis secara online tanpa perlu mengunjungi tempat tersebut.Dapat memberikan keringanan kepada para pelanggan karena para pelanggan dapat melihat dan mengetahui produksi apa saja yang sedang dipamerkan atau di tawarkan pada toko tersebut [4]. Seiring berkembangnya era teknologi tidak memungkinkan hampir seluruh pengguna smartphone tak lepas dari yang namanya internet, penelitian ini menawarkan untuk merancang serta membuat sebuah sistem informasi yang bisa meringankan interaksi jual-beli, persediaan dan transaksi lainya. Pada sistem informasi ini sangat diharapkan dapat membenahi interaksi yang pada proses penjualan dari manual yang biasa dilakukan oleh transaksi sebelumnya, kini dengan adanya sistem ini dapat menjadikan transaksi serta penjualan yang terkomputeras[5]. Dalam pengembangan suatu website, dibutuhkannya beberapa hal yang harus dianalisis khususnya dibagian pembiayaan. Karena rancang bangun system informasi penjualan PT. Duta perfume memiliki system pembayaran agar hasil pendapatan yang dilakukan dapat terilihat [12].

Sistem informasi sebuah sistem yang menyajikan sebuah informasi untuk manajemen pengambilan kebijakan dan menjalankan operasional yang saling berelasi satu sama lain yang berbentuk satu kesatuan untuk mengintegrasikan data, teknologi infomasi dan prosedur-prosedur yang terorganisasi. Atau bisa juga diartikan sebuah kombinasi dari teknologi informasi serta kegiatan pengguna yang menjalankan teknologi guna mendukung jalannya operasi dan manajemen.[6].
Penjualan adalah sebuah parameter paling berpengaruh dalam perusahaan maupun toko dan dunia perbisnisan lainnya. aktivitas terpadu dalam pengembangan berbagai perencanaan strategis yang ditujukan pada upaya pemenuhan kebutuhan dan kepuasan konsumen yang berakhir pada transaksi penjualan dengan memperoleh laba. Atau bisa diartikan sebagai upaya maupun tindakan kongkrit yang dijalankan dalam mendistribusikan suatu produk baik barang maupun jasa yang berasal dari produsen ke konsumen dengan atau tanpa melalui perantara.[7].

Internet adalah suatu jaringan komunikasi global yang menghubungkan milyaran jaringan komputer secara terbuka dengan menggunakan sistem standar global transmission control protocol/ internet protocol suite (TCP/ IP).Ada juga yang menjelaskan bahwa definisi internet adalah International Network, dimana semua tipe dan jenis komputer di seluruh dunia dapat terhubung dengan memakai tipe komunikasi seperti telepon, satelit, dan lainnya. Alamat IP setiap komputer pasti unik dimana berbentuk kombinasi angka yang menunjukkan identitas sebuah komputer pada jaringan internet [8].

Website adalah sebuah kumpulan halaman pada suatu domain di internet yang dibuat dengan tujuan tertentu dan saling berhubungan serta dapat diakses secara luas melalui halaman depan (home page) menggunakan sebuah browser menggunakan URL website. kumpulan informasi yang berbentuk halaman-halaman elektronik atau web page. Sebuah website umumnya terhubung pada sebuah alamat penunjuk yang spesifik. Alamat penunjuk tersebut dinamakan domain, misal Detik.com atau Nesabamedia.com. Website pada umumnya terdiri dari format teks, gambar, table, grafik, kutipan , video, musik, dan format visual lainnya yang menarik bagi pengunjung website tersebut.Sebuah website biasanya bisa diakses secara umum. Kebanyakan website dapat diakses melalui public internet protocol (IP) dalam sebuah jaringan internet. Namun tidak menutup kemungkinan bahwa website tersebut diakses secara offline melalui jaringan 
LAN. Website bisa berupa website pribadi, komersial, pemerintahan, dan website lainnya yang dibuat untuk kepentingan profit maupun non profit yang dipublikasikan secara umum. Selain itu, website juga dapat dibuat untuk tujuan khusus seperti misalnya untuk hiburan, pendidikan, dan juga kepentingan sosial [9]. PHP adalah bahasa pemrograman yang sering disisipkan ke dalam HTML. PHP sendiri berasal dari kata Hypertext Preprocessor. Sejarah PHP pada awalnya merupakan kependekan dari Personal Home Page (Situs personal). PHP pertama kali dibuat oleh Rasmus Lerdorf pada tahun 1995. Pada waktu itu PHP masih bernama Form Interpreted (FI), yang wujudnya berupa sekumpulan skrip yang digunakan untuk mengolah data formulir dari web. Bahasa pemrograman ini menggunakan sistem server-side. Server-side programming adalah jenis bahasa pemrograman yang nantinya script/program tersebut akan dijalankan/diproses oleh server. Kelebihannya adalah mudah digunakan, sederhana, dan mudah untuk dimengerti dan dipelajari. Semenjak PHP menjadi bahasa pemrograman yang open source, pengembang tidak perlu menunggu sampai dengan update terbaru rilis. Pengguna PHP akan lebih baik jika menggunakan versi terbaru. Sehingga jika ada rilis terbaru Anda harus menyesuaikan sistem Anda dengan versi PHP yang paling baru. Meskipun harus menggunakan versi terbaru, biaya untuk maintenance dan web development sangat terjangkau. Bahasa pemrograman PHP membantu Anda untuk mengembangkan aplikasi berbasis web yang cukup kompleks, handal, dan cepat. tergantung dari analisis

Analisis menggunakan spesifikasi bisnis, penggunaan hosting, tingkat pengalaman, kebutuhan aplikasi, dan pengembangan timeframe. Selain itu ada banyak PHP frameworks yang dapat dipilih [10].

MySQL merupakan database engine atau server database yang mendukung bahasa database pencarian SQL. MySQL adalah sebuah perangkat lunak sistem manajemen basis data SQL atau DBMS yang multithread, multi-user. MySQL sebenarnya merupakan turunan salah satu konsep utama dalam database sejak lama, yaitu SQL (Structured Query Language). SQL adalah sebuah konsep pengoperasian database, terutama untuk pemilihan atau seleksi dan pemasukan data, yang memungkinkan pengoperasian data dikerjakan dengan mudah dan cepat secara otomatis. Keandalan suatu sistem database (DBMS) dapat diketahui dari cara kerja optimizer-nya dalam melakukan proses perintah-perintah SQL, yang dibuat oleh user maupun program-program aplikasinya. Sebagai database server, MySQL dapat dikatakan lebih unggul dibandingkan database server lainnya dalam query data. Hal ini terbukti untuk query yang dilakukan oleh single user, kecepatan query MySQL bisa sepuluh kali lebih cepat dari PostgreSQL dan lima kali lebih cepat dibandingkan Interbase[11].

\section{METODE PENELITIAN}

Tahapan pengembangan sistem ini menggunakkan sekuensial linear di mana metode ini sangat cocok untuk mengembangan suatu sistem yang di buat dari awal. Dengan biaya yang relative murah, serta pengembangan yang sangat cepat ,membuat aplikasi dapat di rilis untuk di gunakkan pengguna. Tahap-tahap tersebut terdiri dari Analisis, design Kode dan Testing.

\section{Analisis}

Analisis: Analisi menggunakan Tabel berbasis kebutuhan fungsi pada aplikasi web. Pada tahapan ini dilakukan analisis kebutuhan fungsi yang akan tersedia pada aplikasi web. Proses analisis ini dimulai dari menentukan aktor sebagai pengguna dari aplikasi web. Selanjutnya ditentukan fungsi dan fitur apa saja yang disediakan untuk masing-masing actor tersebut. Hasil dari analisis kebutuhan fungsi akan menjadi 
referensi pada saat merancang struktur, navigasi dan antarmuka.[13]

\section{Desain}

Desain: Menggunakan ERD dan DFD dan desain tampilan menggunkan Figma sebagai mockup tampilan

Pada rancangan suatu sistem, dibutuhkan sebuah wadah untuk menampung data - data yang akan di simpan sebagimana data ini digunakan untuk menampilkan kebutuhan informasi yang akan dibutuhkan oleh user . dengan begitu dibutuhkan sebuah rancangan database untuk untuk merancang kebutuhan analisis infotmasi dari data base tersebut di mana analisis desainnya menggunakan UML dan ERD . setelah data base sudah dirancang , maka selanjutnya akan dirancang tampilan agar user nyaman saat mengakses sistem ini . perancangan tampilan tersebut menggunkan aplikasi figma sebagai mockup tampilan.

\section{Kode}

Kode: Menggunakan Visual Studio Code sebagai Text Editor, Bahasa program mengunnakn PHP dan pengorganisasiannya DBMS menggunakan MySQL

Pengembangan sistem ini menggunkan program Bahasa PHP yang mana Bahasa program ini adalah program yang paling umum untuk membuat sebuah sistem informasi . pengetikkan kode menggunakan Visual Studio Code yang sangat mendukung environment program language PHP. Pengirganisasian suatu DBMS menggunkan MySQL yang umum untuk digunakan

\section{Testing}

Testing: Menggunakan metode black box. Pengujian sistem ini menggunkan Black Box ,Black Box pengujian adalah metode pengujian perangkat lunak yang menguji fungsionalitas aplikasi yang bertentangan dengan struktur internal atau kerja (lihat pengujian white-box). Pengetahuan khusus dari kode aplikasi / struktur internal dan pengetahuan pemrograman pada umumnya tidak diperlukan.

\section{HASIL DAN PEMBAHASAN}

Pada tahap dibawah ini dipaparkan hasil daripada penelitian tersebut yakni perolehan analisis kebutuhan daripada fungsi itu tersendiri, rancangan website, rancangan database, pengujian fungsi serta tampilan User Interface website tersebut.

Berdasarkan perolehan dari analisa kebutuhan fungsi dari website yang hendak di progress yang diperagakan pada tabel 1

Hasil dari rancangan aplikasi website itu tersendiri memperoleh perancangan data design dengan menggunakan model Class Diagram seperti yang ditunjukkan pada gambar 1 dan gambar 2 .

Tabel 1: Kebutuhan Fungsi

\begin{tabular}{|l|l|}
\hline Aktor & Kebutuhan Fungsionalitas \\
(Customer) & $\begin{array}{l}\text { Pengunjung website (user) dapat } \\
\text { menerima perkembangan, serta } \\
\text { setiap progress atau bahkan melihat } \\
\text { informasi diskon atau barang baru } \\
\text { dari Sistem Informasi yang tertera } \\
\text { pada website tersebut. }\end{array}$ \\
\hline $\begin{array}{l}\text { Keranjang } \\
\text { Belanja }\end{array}$ & $\begin{array}{l}\text { Keranjang belanja berfungsi untuk } \\
\text { menyimpan data belanjaan yang } \\
\text { hendak dibeli atau tidaknya oleh } \\
\text { customer, keranjang belanja pada } \\
\text { sistem ini berfungsi sebagai tempat } \\
\text { penyimpana sementara antara user } \\
\text { dengan items }\end{array}$ \\
\hline Admin & $\begin{array}{l}\text { Fungsi daripada admin tersendiri } \\
\text { yaitu dapat menerima akses atau } \\
\text { jalan man } \\
\text { mengorganisasikan (mengendalikan) } \\
\text { data items ,dan informasi keranjang } \\
\text { belanja yang ditampakkan untuk } \\
\text { customer }\end{array}$ \\
\hline
\end{tabular}

Model-model tersebut telah terhubung ke database, pada view user melakukan pengecekan username dan password 
kemudian verify login untuk mengakses data ke dalam sistem tersebut. Lalu pada bagian admin, seorang yang admin yang bertugas disini juga harus memiliki sebuah akun email dan juga namanya yang berfungsi untuk mengelola website tersebut, admin juga dapat menambah barang, mengedit, dan menghapus beberapa items yang tertera pada website tersebut.

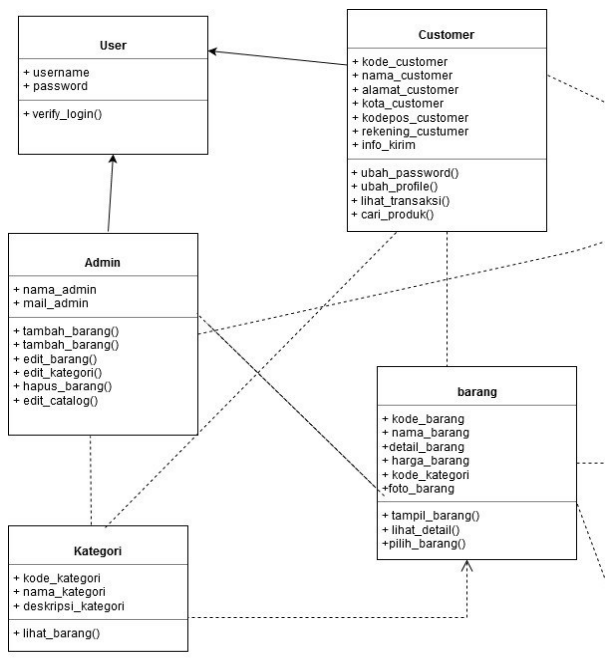

Gambar 1. Class Diagram (1)

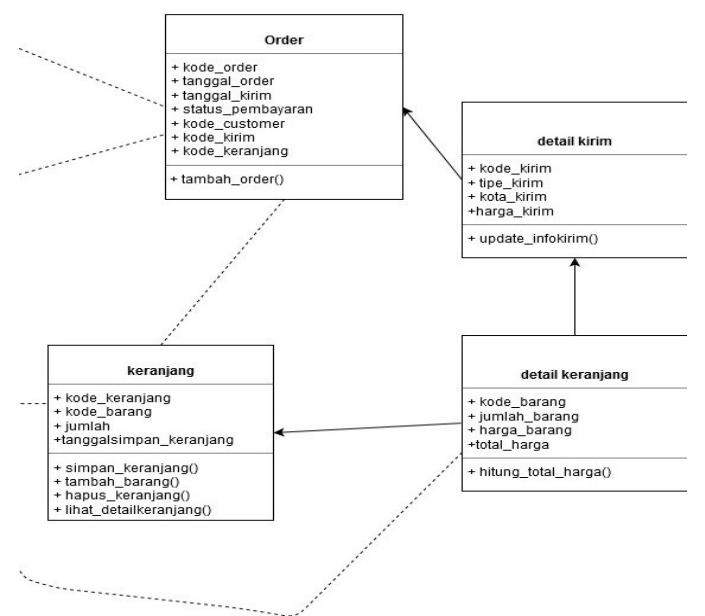

Gambar 2. Class Diagram (2)

Interface kategori memiliki beberapa atribut berupa nama kategori, kode kategori, serta deskripsi kategori tersebut, dan juga terdapat sebuah method dengan nama lihat barang(), artinya seorang user dapat melihat items tersebut sudah terjual atau masih terdapat stok barang, pada bagian interface keranjang terdapat atribut public kode keranjang, kode barang, jumlah, dan tanggal simpan keranjang, keranjang ini berfungsi untuk menyimpan data sementara yang di kelola oleh user, artinya user telah memilih barang belanjaan namun belum terjadi transaksi, dan barang yang telah dipilih oleh user tersebut akan tersimpan di dalam keranjang belanja.

Pembuatan rancangan database ini menggunakan $M y S Q L$ dengan XAMPP dan dikelola dengan menggunakan PhpmyAdmin. Pada gambar 3 merupakan skema table yang di gunakan dalam database

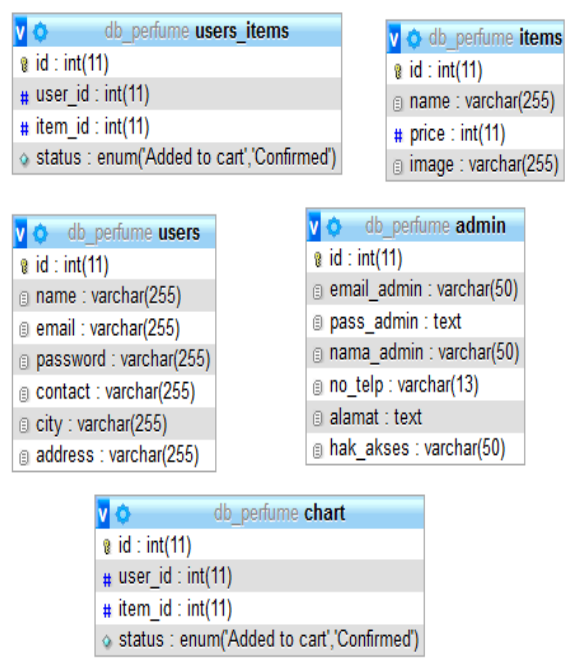

Gambar 3. Rancangan Database

User Interface atau Antarmuka Aplikasi Website

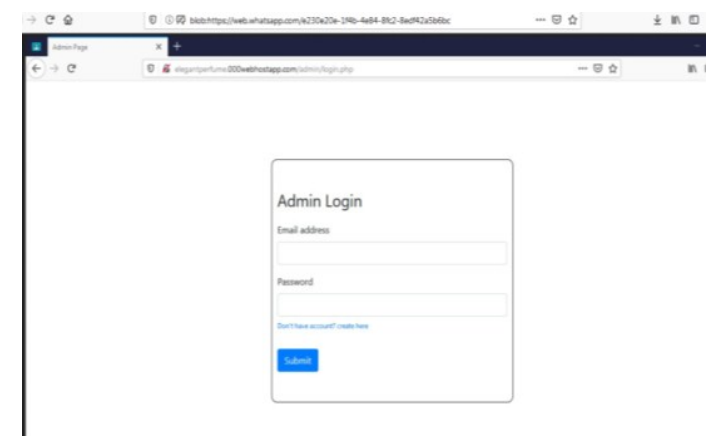

Gambar 4. Halaman Login Admin

Gambar 4 merupakan halaman admin yang mana setelah admin melakukan login account maka akan menampilkan data 
entry barang untuk memasukkan deksripsi serta harga barang yang akan dijual seperti gambar 5

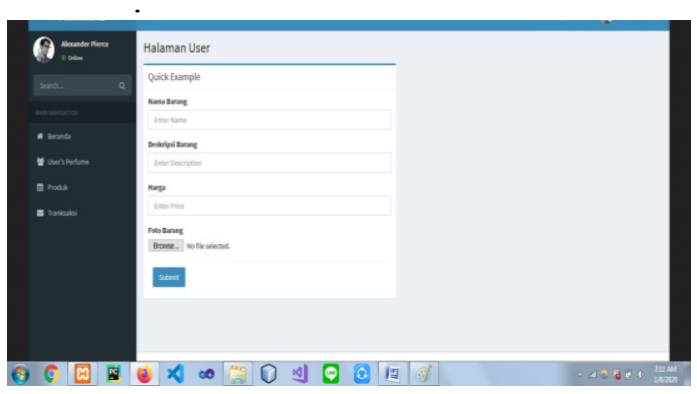

Gambar 5. Halaman Input Barang

Pada Gambar 5, merupakan bagian halaman produk Admin yang dapat melihat, mengelola barang mulai dari menambah, mengubah, atau menghapus barang, seperti pada gambar 7 :

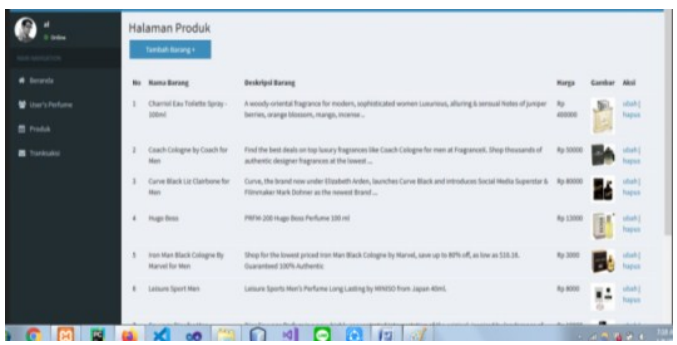

Gambar 6. Halaman Kelola Barang

Gambar 6 menjelaskan bagaimana produkproduk yang akan ditampilkan di bagian client-side melalui admin-side.

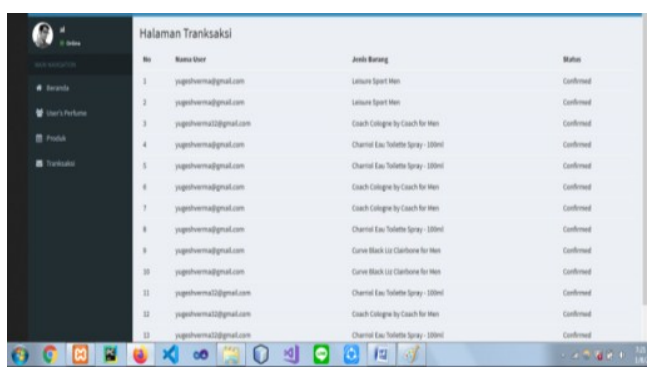

Gambar 7. Halaman Kelola Barang

Pada Gambar 7 merupakan halaman transaksi, artinya admin dapat melihat pembeli barang dengan nama, jenis barang apa yang dibeli serta status dari pembelian tersebut.

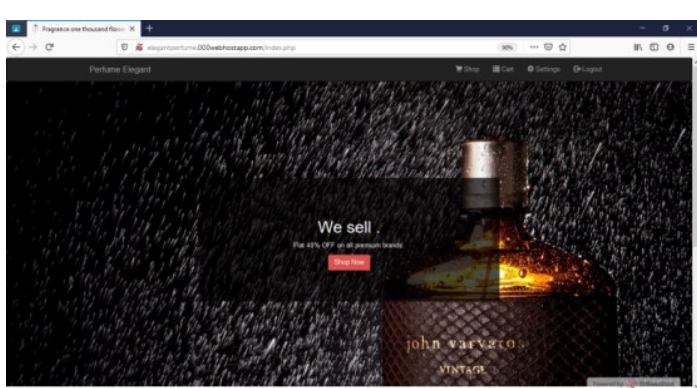

Gambar 8. Halaman Index User

Gambar 8 adalah bagian antarmuka untuk para pengunjung yang ingin membeli ataupun melihat-lihat barang yang terdapat pada website tersebut.

Setelah user menakan tombol aktivitas sell now maka akan menuju halaman produk yang menampilkan jenis-jenis barang, deskripsi barang serta harga dari barang yang tertera, seperti pada Gambar 9.

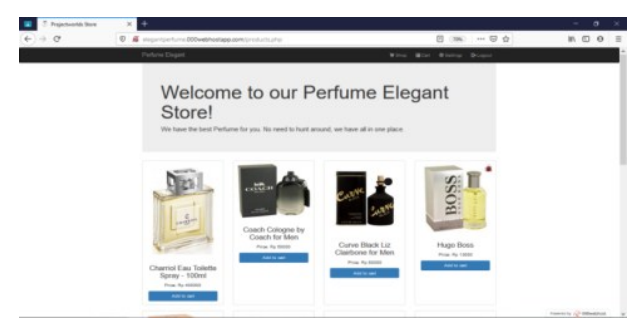

Gambar 9. Halaman Produk

Pada gambar 9 merupakan dashboard client-side dimana tempat melihat dan membeli barang yang diinginkan.

Apabila user telah memilih barang untuk dibeli maka user akan diarahkan untuk mengisi halaman login. Seperti pada gambar 10.
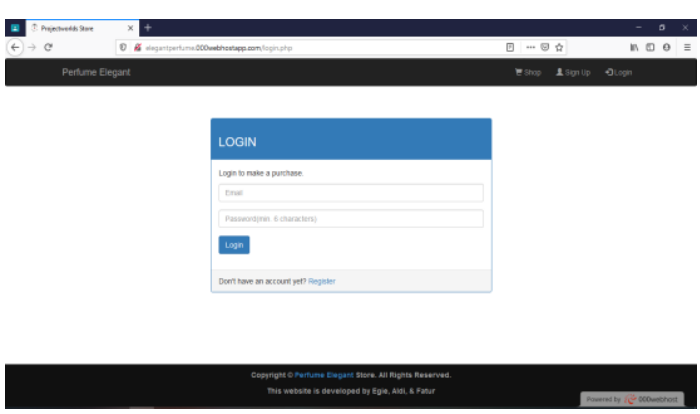

Gambar 10. Halaman Login User 
Ketika user telah melakukan verifikasi login maka barang yang dipilih oleh user akan dimasukkan kedalam halaman keranjang, setelah itu akan diarahkan menuju halaman transaksi seperti pada Gambar 11.

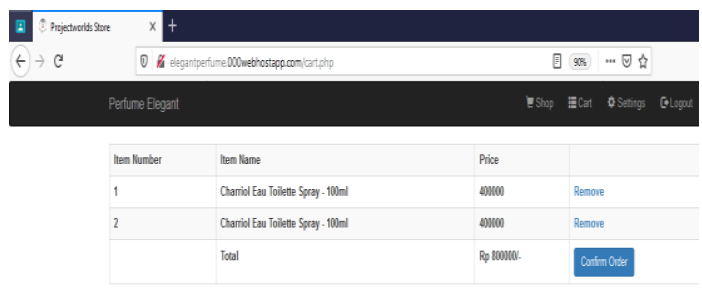

\section{Gambar 11: Halaman Keranjang Produk}

\section{Pengujian Fungsi}

Pengujian fungsi yang dioperasikan dengan menggunakan metode blackbox, yaitu setiap bagian pada fungsi pada website akan dicek terdapat sebuah kesalahan atau tidak. Pengujian fungsi ditunjukkan oleh tabel 2.

Tabel 2: Pengujian Fungsi

\begin{tabular}{|c|c|c|}
\hline Unit Uji & Keterangan & $\begin{array}{l}\text { Hasil } \\
\text { Uji }\end{array}$ \\
\hline $\begin{array}{l}\text { Validasi } \\
\text { login } \\
\text { dan } \\
\text { Verifika } \\
\text { si login }\end{array}$ & $\begin{array}{l}\text { Fungsi ini digunakan } \\
\text { untuk memproses input } \\
\text { data, dan mengelola } \\
\text { data masuk yang } \\
\text { dikelola oleh } \text { user }\end{array}$ & OK \\
\hline $\begin{array}{l}\text { Menam } \\
\text { pilkan } \\
\text { Data } \\
\text { Barang }\end{array}$ & $\begin{array}{lr}\text { Pada fungsi } & \text { ini } \\
\text { digunakan } & \text { untuk } \\
\text { menampilkan } & \text { data } \\
\text { barang yang } & \text { terdapat } \\
\text { pada } & \text { database } \\
\text { tb_barang } & \end{array}$ & OK \\
\hline $\begin{array}{l}\text { Create, } \\
\text { Read, } \\
\text { Delete, }\end{array}$ & $\begin{array}{l}\text { Fungsi ini digunakan } \\
\text { untuk mengelola stok } \\
\text { barang dan menambah, }\end{array}$ & $\overline{\mathrm{OK}}$ \\
\hline
\end{tabular}

\begin{tabular}{|c|c|c|}
\hline $\begin{array}{l}\text { and } \\
\text { Update }\end{array}$ & $\begin{array}{l}\text { mengedit ataupun } \\
\text { menghapus yang } \\
\text { dilakukan olhe admin }\end{array}$ & \\
\hline $\begin{array}{l}\text { Menam } \\
\text { pilkan } \\
\text { data } \\
\text { barang } \\
\text { masuk } \\
\text { kedalam } \\
\text { keranjan } \\
\text { g } \\
\text { belanja }\end{array}$ & $\begin{array}{lr}\text { Fungsi ini digunakan } \\
\text { untuk melihat barang- } \\
\text { barang yang dipilih } \\
\text { oleh user yang masuk } \\
\text { kedalam } r \text { keranjang } \\
\text { belanja } & \text { untuk } \\
\text { menyimpan } & \text { data } \\
\text { barang sementara } \\
\text { terjadi transaksi } \\
\text { pihak antar }\end{array}$ & $\mathrm{OK}$ \\
\hline
\end{tabular}

Validasi login dan Verifikasi login. Fungsi ini digunakan untuk memproses input data, dan mengelola data masuk yang dikelola oleh user. Fungsi berjalan dengan baik.

Menampilkan Data Barang . Pada fungsi ini digunakan untuk menampilkan data barang yang terdapat pada database tb_barang. Fungsi berjalan dengan baik.

Create, Read, Delete, and Update. Fungsi ini digunakan untuk mengelola stok barang dan menambah, mengedit ataupun menghapus yang dilakukan olhe admin. Fungsi berjalan dengan baik.

Menampilkan data barang masuk kedalam keranjang belanja. Fungsi ini digunakan untuk melihat barang-barang yang dipilih oleh user yang masuk kedalam keranjang belanja untuk menyimpan data barang sementara terjadi transaksi antar pihak. Fungsi berjalan dengan baik.

\section{SIMPULAN}

Bedasarkan hasil dari rancang bangun sistem informasi e-commerce yang telah dilakukan dapat diambil beberapa kesimpulan :

1. Sistem mempunyai fasilitas untuk menyimpan data users dan data admin yang dilengkapi dengan username dan password untuk keamanan sistem, dapat memberikan informasi mengenai status order barang kepada costumer. 
2. Menggunakan sebuah fitur hositng agar user dapat mengakses layanan $e$ commerce PT. Duta Perfume. Hal ini dapat membuat user membeli barang yang diinginkannya.

\section{Saran}

Berdasarkan kesimpulan yang Telah diambil, dapat diberikan saran-saran untuk pengembangan sistem dan perawatan sistem:

1. Untuk pengembangan, dapat ditambahkan fasilitas pembayaran secara online dengan memanfaatkan kartu kredit atau pembayaran elektronik lainnya.

2. Untuk penambahan fasilitas secaara online diperlukan juga pengembangan dalam hal keamanan transaksi dan keamanan data.

3. Penambahan Validasi pembayaran users sebagai bukti pembayaran

\section{DAFTAR PUSTAKA}

[1] Galiha, S. T., Mustafidb, \& Sugihartob, A. (2011). Rancang Bangun Portal E-Commerce Semarang-Handycraft Berorientasi Obyek . Jurnal Sistem Informasi Bisnis , 16-21.

[2] Aryanto, A., \& Tjendrowaseno, T. I. (2013). Pembangunan Sistem Penjualan Online Pada Toko Indah Jaya Furniture Surakarta. SpeedSentra Penelitian Engineering Dan Edukasi, 4(4).

[3] Wulandari, W., \& Aprilia, S. (2017). Sistem Informasi Penjualan Produk Berbasis Web Pada Chanel Distro Pringsewu. Jurnal Tam (Technology Acceptance Model), 4, 41-47.

[4] Hasanah, U. (2013). Sistem Informasi Penjualan On Line Pada Toko Kreatif Suncom Pacitan. IJNS-
Indonesian Journal on Networking and Security, 4(3).

[5] Dewi, L. C. (2013). Sistem informasi pembelian, persediaan, dan penjualan untuk Apotek. ComTech: Computer, Mathematics and Engineering Applications, 4(1), 430-442.

[6] Erinawati, H. D. (2013). Pembangunan Sistem Informasi Pembayaran Sekolah Pada Sekolah Menegah Atas (SMA) Negeri 1 Rembang Berbasis Web. Speed-Sentra Penelitian Engineering Dan Edukasi, 4(4).

[7] Pakaja, F., Naba, A., \& Purwanto, P. (2012). Peramalan Penjualan Mobil Menggunakan Jaringan Syaraf Tiruan dan Certainty Factor. Jurnal Eeccis, 6(1), 23-28.

[8] Rahardjo, B. (2001). Aspek Teknologi Dan Keamanan Dalam Internet Banking. PT Insan Indonesia. PT INDOCISC.

[9] Suhartanto, M. (2017). pembuatan website sekolah menengah pertama negeri 3 delanggu dengan menggunakan php dan mysql. SpeedSentra Penelitian Engineering Dan Edukasi, 4(1).

[10] Yuliano, T. (2007). Pengenalan Php. IlmuKomputer. Com.

[12] Ramadhani, S., Urifatun, A., \& Masruro, S. T. (2013). Rancang Bangun Sistem Informasi Geografis Layanan Kesehatan Di Kecamatan Lamongan Dengan PHP MySQL. Jurnal Teknika, 5(2).

[13] Yaddarabullah, Y., Agusalim, L., \& Karim, M. (2018). Pengembangan Aplikasi Web Pemetaan Perkembangan Koperasi di Indonesia Berbasis Web Modeling Language. Jurnal KomtekInfo, 5(2), 1-10. 